\title{
Violencia parapolicial en Bahía Blanca, 1974-1976. Delgados límites entre lo institucional y lo ilegal en la lucha contra la subversión apátrida
}

Ana Belén Zapata*

Resumen: En este artículo analizaremos algunos aspectos de la violencia que llevaron a cabo grupos parapoliciales en la ciudad de Bahía Blanca - provincia de Buenos Aires -, entre 1974 y 1976. Podemos hablar de este período como un momento en el cual se gestaron ciertas condiciones de posibilidad para la ruptura democrática que se produjo con el golpe de Estado que instauró la dictadura en Argentina luego del 24 de marzo de 1976. Esta idea de fondo atraviesa el presente artículo donde nos proponemos analizar las formas que adquirió la violencia de extrema derecha en Bahía Blanca. Puntualmente nos preguntamos ¿qué característica tuvieron esos crímenes y atentados previos a 1976?, ¿cuánto conocía de ellos la Dirección de Inteligencia de la Policía de Buenos Aires (DIPBA) como órgano de carácter estatal?, ¿qué informes elaboraban al respecto los agentes de la DIPBA?, ¿cómo se imbricaron las prácticas y discursos de actores dentro del sistema político, con las acciones ilegales y parapoliciales en la llamada "lucha antisubversiva" ya instalada antes del golpe de Estado?

Palabras claves: Violencia parapolicial. Represión. Servicios de Inteligencia. Ilegalidad.

* Licenciada y Profesora en Historia de la Universidad Nacional del Sur de Bahía Blanca. Doctoranda en Historia de la Universidad Nacional de La Plata. Becaria doctoral del Consejo Nacional de Investigaciones Científicas y Técnicas (CONICET). Lugar de Trabajo: Instituto de Investigaciones Gino Germani/ Facultad de Ciencias Sociales Universidad de Buenos Aires, Argentina. E-mail: aymarazapata@yahoo.com.ar 
Invito al señor diputado Ponce a que me acompañe - sin ametralladoras- a una reunión de estudiantes de Babia Blanca para que compruebe la veracidad de mis afirmaciones. Ante el juez federal doctor García se han presentado ocho denuncias por portación de armas largas por gente en la universidad. Cuando la Policía Federal concurrió a la universidad hace cinco días en oportunidad del secuestro del interventor Lucio Fernández, ante la presencia de los matones a sueldo - tan a sueldo son que uno de ellos no quería trabajar porque no se le abonaba- la propia Policía Federal se retiró de la universidad. Diputado Héctor Sandler Diario de Sesiones de la Cámara de Diputados de la Nación, 4 de septiembre $1974^{1}$

En este artículo analizaremos algunos aspectos de la violencia que llevaron a cabo grupos parapoliciales en la ciudad de Bahía Blanca - provincia de Buenos Aires-, entre 1974 y 1976. Podemos hablar de este período como un momento en el cual se gestaron ciertas condiciones de posibilidad para la ruptura democrática que se produjo con el golpe de Estado que instauró la dictadura en Argentina luego del 24 de marzo de 1976. Esta idea de fondo atraviesa el presente artículo donde nos proponemos analizar las formas que adquirió la violencia de extrema derecha en Bahía Blanca. Puntualmente nos preguntamos ¿qué característica tuvieron esos crímenes y atentados previos a 1976?, ¿cuánto conocía de ellos la Dirección de Inteligencia de la Policía de Buenos Aires (DIPBA) como órgano de carácter estatal?, ¿qué informes elaboraban al respecto los agentes de la DIPBA?, ¿cómo se imbricaron las prácticas y discursos de actores dentro del sistema político, con las acciones ilegales y parapoliciales en la llamada "lucha antisubversiva" ya instalada antes del golpe de Estado?

Durante los años 1973 y 1976 en Argentina se vivió el retorno de Juan Domingo Perón luego de un exilio de 18 años. En mayo de 1973, con las elecciones que ganó el peronismo, comenzó un nuevo período constitucional luego de años de continuidad dictatorial y de casi dos décadas de proscripción al justicialismo. Eran tiempos de fuerte movilización social y un conjunto de nuevas organizaciones 


\section{Ana Belén Zapata}

políticas de izquierda o del peronismo de izquierda, adquirieron en la escena pública importante relevancia. Así como también organizaciones que optaron por la lucha armada como el PRT-ERP o Montoneros. Muchas de las organizaciones de jóvenes militantes que integraban las diversas ramas de la Juventud Peronista (JP) ${ }^{2}$ se encontraron identificados con el proyecto de la llamada "patria socialista” y vieron en Perón la promesa de su concreción. Pero paulatinamente, y de forma exponencial a partir de la masacre de Ezeiza, las verdaderas intenciones del líder quedaron en evidencia con su abierta condena hacia estos sectores considerados "extremistas" y su apoyo cada vez más notable a la ortodoxia peronista.

Es sabido que la Alianza Anticomunista Argentina - organización más conocida como Triple $\mathrm{A}^{3}$ - nació en los pasillos del Ministerio de Bienestar Social como obra del Ministro José López Rega, durante el gobierno de Juan Domingo Perón, y luego de su muerte, el de su esposa María Estela Martínez de Perón o "Isabel". Horacio Paino, un arrepentido ex miembro de dicha organización, detallaba en su libro cuestiones sobre la logística y los operativos que realizaban y cómo se financiaban desde el Ministerio, utilizando incluso el edificio gubernamental para almacenar el armamento. (PAINO, 1984) Esta organización estructuró una red de contactos que le permitió su expansión en el plano nacional, dándole operatividad a partir de ciertas personalidades del ámbito policial, militar y de organizaciones sindicales. Se montó una estructura clandestina conducida por Alberto Villar, Juan Ramón Morales y Rodolfo Eduardo Almirón miembros de la Policía Federal, y Miguel Ángel Rovira suboficial de la misma fuerza. Además de miembros de la Policía Federal también estuvo integrada por sindicalistas, militantes del más ortodoxo peronismo, sectores ultraderechistas y matones a sueldo.

El objetivo de la Triple A era terminar con aquellas personas que consideraban parte de la "subversión apátrida". Los ataques de esta organización comenzaron el 21 de noviembre de 1973, cuando con una bomba casi terminan con la vida del senador del partido radical Hipólito Solari Yrigoyen. Las futuras víctimas se daban a conocer desde la publicación de listas del terror. Incluso muchas de ellas fueron condenadas a muerte en la revista del peronismo más ortodoxo, El Caudillo de la Tercera posición, publicada en esa época 
por Felipe Romeo, que oficiaba de voz pública de la organización. Específicamente en la sección llamada "Oírme" se planteaba el enfrentamiento político con personalidades que sufrieron sus acechos, como los diputados Héctor Sandler y Jesús Porto, Rodolfo Ortega Peña, el padre Carlos Mugica, entre otros.

Sobre la violencia ejercida por esta extrema derecha y sus vínculos con gobierno de Perón se ha escrito bastante. Pilar Calveiro (2005) plantea que la consigna de eliminación de la llamada "subversión" fue previa al golpe militar de 1976 y se pudo observar con la creación de la Triple A desde fines de 1973, incluso antes que muriera Perón. La autora enfatiza que ya se había tomado la decisión de aniquilar a todo actor protagonista de cualquier acción considerada terrorista, y finalmente la muerte del líder no hizo más que acelerar lo que ya se había puesto en marcha desde antes: la aniquilación, por cualquier vía, de los sectores considerados "extremistas". Finalmente, el golpe de Estado de 1976, convirtió en práctica de Estado la eliminación y desaparición no sólo de los grupos armados o radicales y sus entornos sino de toda disidencia.

Por su parte Héctor Lobbe sostiene que

[...] la acción violenta encarada por bandas armadas, protegidas y estimuladas desde el Estado [dio] cuenta del grado de impotencia por parte del régimen para garantizar su 'orden', al ser insuficientes los instrumentos legales y represivos formales de control, ante la activación de la creciente protesta social (2009, p. 55).

En una lógica similar, Marina Franco (2012) plantea la necesidad de salir del lugar común que señala a López Rega como la única encarnadura de la represión clandestina en esta época. En cambio, nos propone comenzar a observar otros múltiples aspectos que hicieron a la política estatal y legitimada, la cual formó parte de la persecución a la llamada "subversión" y contra el "enemigo interno de la nación" en pos de la tan nombrada "Seguridad Nacional".

En este sentido, cabe analizar la cuestión del deterioro institucional de Estado como "un proceso colectiva y socialmente alimentado" que se dio durante estos años en términos de fenómeno 
histórico. Franco intenta demostrar cómo la avanzada represiva tuvo lugar en este gobierno democrático a partir de un entramado de políticas y prácticas institucionales articuladas con las de carácter clandestino o para estatal.

Sobre la cuestión de la violencia, o el "problema de la violencia" en esos años, es interesante el planteo de la autora, ya que advierte que "la violencia" fue generalmente referenciada en las acciones armadas de la guerrilla de izquierda o sectores del peronismo de la Tendencia como enemigos ajenos al "ser nacional". Al centrarse solo en esa violencia, en cierta forma, se dejaba de lado la ejercida de forma paraestatal desde sectores de la extrema derecha. Franco afirma que los hechos de violencia de la llamada "subversión" operaban, en los diarios del momento, como organizadores de una realidad difícil de codificar solamente desde ese soporte, ya que los episodios de asesinato, secuestros, explosivos eran comunes, cotidianos y terminaban siendo "rutinizados y banalizados".

Así, la 'subversión' se transformó en un organizador de las relaciones político-discursivas (a riesgo de anular toda comprensión real de la conflictividad política) y, su contraparte, el discurso "antisubversivo", se constituyó en un ordenador de las prácticas legales, más allá de los reparos y límites que algunas fuerzas manifestaron al respecto. (FRANCO, 2009, p. 21)

\section{La violencia parapolicial en Bahía Blanca ${ }^{4}$}

En Bahía Blanca, entre 1973 y 1976 podemos leer desde la prensa los numerosos hechos de violencia que son detallados especialmente por el diario local La Nueva Provincia (en adelante LNP) que toma muy en serio su misión de "vocero" de las Fuerzas Armadas; en especial, si se trata de contarle a la población cuántas armas se incautaron en un "operativo antisubversivo" o cuantas pintadas "subversivas" encontraron en las paredes de las calles bahienses, o cuantos "extremistas" del PRT-ERP o Montoneros fueron detenidos. Sin embargo también encontramos notas referidas 
a sangrientos asesinatos a militantes, obreros, estudiantes o explosiones dentro de locales partidarios -como los que se produjeron el 27/01/1974 cuando estallaron bombas en las sedes del Partido Socialista de los Trabajadores (PST) donde también funcionaba la Juventud Socialista de Avanzada y en la sede local del Partido Comunista. Estos dos episodios se dieron con un intervalo de diez minutos entre un hecho y el otro (LNP, 27/01/1974). La seguidilla de violentos crímenes tuvo lugar entre los años 1974 y 1975. Con una mayor virulencia en este último.

El 22/09/1974 fue secuestrado de su casa y luego asesinado Jesús "Negrito" García. Era militante del FAS de 18 años de edad, obrero y delegado de la construcción en una obra de Ingeniero White. Su cuerpo fue encontrado horas después totalmente baleado, en un paraje conocido como "El Pibe de oro" en el camino que une Cerri con la ruta 3. (LNP, 23/09/1974) Como afirma Julia Giménez, "tiempo después la Triple A se atribuyó esta muerte, argumentando la peligrosidad del joven" (GIMÉNEZ, 2008, p. 119). El "Negrito" trabajaba en una obra de la empresa Interamericana donde se construía un barrio de monoblocks en Ingeniero White. El era delegado de la obra y había sido echado varias veces por su combatividad a la hora de reclamar por mejores condiciones de trabajo. La madre y la hermana de Jesús recordaban las amenazas que había sufrido tiempo antes del secuestro por "gente de la CGT". Su madre afirmaba ${ }^{6}$ " $y$ después, con quien se llevan a mi hijo es con el auto ese que también lo usaba el de la CGT... Ponce ${ }^{7} . . . "$ Su hermana explicaba las amenazas que sufrió su hermano:

Había sido amenazado en la ruta. Había sido amenazado. Habían querido quitarle el trabajo, lo habían cesanteado [...] y eran fachos de la...lo que pasa que estos eran legales ¿quiénes eran? Los de la CGT. Así que ya había tenido problemas él con ellos. Y creo que una de las cosas que más les molestó es que cuando a él lo echan del laburo, de la obra en construcción, la gente hace paro para que lo reincorporen, porque era delegado él dentro de la obra. Hace paro y después se empezaron a plegar todas las otras obras para que lo reincorporaran. Eso fue su certificado de defunción. ${ }^{8}$ 
El día 21/03/1975 durante la misma madrugada se produjeron cuatro hechos que, se podrían interpretar, fueron respuesta al asesinato del subcomisario José Héctor Ramos por parte de Montoneros ${ }^{9}$ la noche anterior. En primer lugar, un grupo de hombres armados ingresaron en una vivienda de religiosos en el Instituto Superior Juan XXIII y balearon al cura salesiano Carlos Dorñak provocando también incendios al arrojar explosivos en el lugar. Este atentado en realidad habría estado dirigido al padre Benito Santecchia quien también vivía allí.

Virginia Dominella asegura que en un volante de la Triple A distribuido el 1 de mayo de 1975 en Buenos Aires, el apellido de Santecchia aparecía junto a los de Mugica, Angelelli, Gera, Vetrano, Llorens y Paoli donde se los catalogaba de "revolucionarios rojos, dependientes de Moscú y la sinárquica CIA... Los tercermundistas están con el ERP, la violencia y la ametralladora. Los tercermundistas están contra el pueblo, contra Perón y contra la Patria" (VANZINI apudDOMINELLA, 2010, p. 27). La misma noche en que se produjo el atentado en el Juan XXIII, fue asesinada Marisa Mendivil de Ponte cuyo cuerpo, desfigurado por los balazos, fue encontrado cerca del paraje "Landa" a la altura del kilómetro 15 de la ruta 35. Por otra parte, explotó una bomba en la casa de Jorge Riganti - militante de la Juventud Universitaria Peronista (JUP) - Y fue secuestrado Fernando Aldubino, estudiante de Filosofía y Letras en la UNS y también militante de la JUP, su cuerpo fue encontrado al día siguiente acribillado por las balas a un costado de la ruta 35 a $10 \mathrm{~km}$ del centro de Bahía Blanca. (LNP, 24/03/1975)

David "Watu" Cilleruelo, estudiante de Ingeniería, fue asesinado el 3/04/1975 en los pasillos de la Universidad Nacional del Sur (UNS). Era secretario de la Federación Universitaria del Sur y militante de la Federación Juvenil Comunista. Los testigos presenciales del hecho aseguran que quien lo asesinó, a sangre fría y en público de un balazo, fue Jorge Oscar Argibay miembro de la custodia armada del rector Remus Tetu ${ }^{10}$. Tetu había realizado contrataciones de agentes para prestar servicios de "seguridad y vigilancia" en la institución, estas personas figuran en resoluciones de la UNS del 25 de marzo; 4, 17, 22 de abril; 21 de mayo y 15 de septiembre todas del año 1975. Entre las personas contratadas se 
encuentran Argibay junto otros ex integrantes de fuerzas armadas y de seguridad, varios custodios de la CGT y miembros de la Juventud Sindical Peronista (JSP).

Uno de los testigos del asesinato de Watu lo recordaba de esta forma:

En ese momento cuando a él lo asesinaron era un día de inscripción, al día siguiente estaba la asamblea para constituirse por primera vez la Federación Universitaria del Sur, donde Watu ya había sido designado secretario general [...] Estábamos desarrollando una actividad muy común en esa época que era volantear, informando a los estudiantes los que iba a pasar al día siguiente en la asamblea. El está con nosotros, se retira del ala de ingeniería, agarra hacia el hall central, lo para Argibay y el grupo de matones, le piden los documentos, él se niega a entregar los documentos pega media vuelta y cuando pega media vuelta a un metro de distancia le disparan, le hacen un disparo en la nuca. Yo soy uno de los primeros que regresa y me encuentro con Watu. Se arrima Argibay, se arrodilla lo da vuelta y lo reconozco a Watu, me apunta y me dice "pobrecito, se golpeó la cabeza contra la pared"11.

El 25/06/1975 fueron encontrados los cuerpos de Daniel Eduardo del Libano Elorrieta, estudiante de la UNS en la carrera de Contador, Angel E. Ogues y Ovidio Oscar Ancel. El cuerpo sin vida del primero fue hallado en las afueras de la ciudad en un camino en la prolongación de la avenida Alem pasando la ruta de empalme. El de Ogues se encontró con aproximadamente 90 impactos de bala en el camino Hormiga cercano al paraje "Landa" y el cadáver de Ovidio Ancel - también con muchos balazos - lo encontraros en la "Cueva de los leones" a 10 kilómetros de la ciudad junto a la ruta 33. (LNP, 26/06/1975) Ese mismo día, también se encontró otro cuerpo al final de la calle Zelarrallán, a 200 metros de la ruta de empalme. Este cuerpo pertenecía a Carlos Anibal Naka Dakare otro estudiante de la carrera de Ingeniería de la UNS (LNP, 28/06/1975). 
Fue asesinado con cinco balazos, con un arma de calibre 32 similar a la utilizada en el asesinato de Daniel del Libano Elorrieta.

Un mes más tarde, el 26/07/1975 fueron asesinados dos albañiles Hugo Ardiles y Orlando Walker de 25 y 26 años respectivamente. Ambos fueron encontrados muertos por heridas de balas. Como en el caso anterior, también los hallaron en la intersección de Zelarrallán con el camino de empalme entre las rutas 33, 35 y 3 sur, en las afueras de la ciudad. Y los asesinatos continuaron, a fines de octubre del mismo año se encontraron los cuerpos sin vida del locutor de radio Mario Oscar Golberg junto a los de Nélida Ester Guiorzzo y Hugo Alberto Vitta, este último estudiante de Bioquímica de la UNS. Los tres cuerpos sin vida se hallaron también en el paraje "Landa" a las afueras de la ciudad. En la autopsia "se indicó que Golberg y la mujer tenían impactos de balas en distintas regiones de la cabeza al igual que Vita, que presentaba además otras heridas en el cuerpo" (LNP, 30/10/1975). El 18/11/1975 fue secuestrado Carlos Davit, el era de Guatraché, estudiaba la carrera de Contador en la UNS y también militaba en la JUP. Su cuerpo apareció acribillado a balazos colgado con un cinturón del puente ferroviario sobre la ruta 3 . El 6/12/1975 fueron asesinados tres estudiantes más, ahora de la carrera de Geología, José Alberto Surace, Gabriel Ganuza y Julio García. Los encontraron acribillados a balazos en el kilómetro 102 de la ruta 35.

Además de todos estos hechos, en varias oportunidades se pusieron explosivos en casas de docentes tanto de la UNS con de la Universidad Tecnológica Nacional (UTN) durante 1975.

Estos son algunos de los sangrientos episodios en Bahía Blanca en esa época, existe la posibilidad de que hayan existido otros, quizás no denunciados o no publicados en los medios de comunicación. Podemos ver que el modus operandi se repite en varios de estos casos, se trata de militantes de izquierda o del peronismo de izquierda, de obreros, y - en su mayoría - de estudiantes de la UNS con algún tipo de participación en la política estudiantil. Algunos fueron secuestrados de sus casas y luego encontrados con numerosos impactos de bala en sus cuerpos tirados mayormente en lugares comunes, todos en las afueras de Bahía Blanca como la 
zona de empalme de rutas, el paraje "Landa", el paraje "La Cueva de los leones" o el "Pibe de Oro".

\section{¿Qué dice la DIPBA ${ }^{12}$ sobre algunos de estos hechos de violencia?}

La idea de indagar en los documentos de la Dirección de Inteligencia de la Policía de Buenos Aires (DIPBA) sobre estas situaciones de violencia parapolicial surgió en primera instancia a partir de la inquietud por saber cuánto de estos hechos de violencia ilegal y clandestina informaban (o no) organismos que producían material de inteligencia de carácter estatal, pero del orden de lo "secreto, confidencial y reservado". Aquí me interesaba ver cómo se imbricaba el conocimiento de estos crímenes en la esfera institucional - para el caso - la Policía de la Provincia de Buenos Aires, dentro de un contexto democrático como lo fue el tercer gobierno peronista.

Un documento fundacional de la DIPBA de 1956 explicita
sus misiones y objetivos. La palabra inteligencia está asociada
a prácticas activas, 'preventivas', sistemáticas y analíticas:
buscar, valorizar, investigar 'para conjurar una posible alteración
pública de los ordenes sindical, cultural, económico, político, etc.'Es
decir: quedan delineadas áreas de trabajo y registro que serán
las 'mesas y factores' en las que se organizó la información del
Archivo así como la estructura de la obtención de la misma
('búsqueda', 'delegaciones', 'subdelegaciones'). Otro rasgo
fundacional que expresa el texto se refiere a las prioridades
o 'blancos' hacia donde orientar las tareas de inteligencia: el
'comunismo' y la actividad sindical (FUNES, 2007, p. 140).

También Julieta Rostica menciona la existencia de informes de inteligencia realizados sobre el accionar de la Triple A, e incluso cómo los mismos operan en el marco en las internas entre las fuerzas armadas y policiales en el gobierno de "Isabel" Perón. 


\section{Ana Belén Zapata}

Fue entonces cuando comenzaron los acercamientos de la línea militar golpista hacia Isabelita. El almirante Massera anteriormente le había entregado a Ricardo Balbín, dirigente del radicalismo, un informe de inteligencia redactado por su arma que revelaba el accionar de la Triple A bajo el ala del Ministro, con el objetivo de que él mismo se lo entregara a Isabel. El acercamiento entre Massera e Isabel produjo el decreto que dio cobertura legal a la acción del Ejército contra la guerrilla en Tucumán, tarea que hasta el momento correspondía a los cuerpos policiales (ROSTICA, 2011, p. 45).

Como un a priori, entendía que la DIPBA en su función de espiar y registrar al llamado "delincuente subversivo" (como denominan incluso a una de sus Mesas de clasificación de información) tendría cierto tipo de identificación con estas bandas parapoliciales con las que compartían "enemigo político". Sin embargo me interesaba observar las formas en las que se expresaba esta "empatía" en los distintos informes.

Como ya explicamos, el "Negrito" García fue secuestrado y asesinado en septiembre del '74, sobre este hecho la DIPBA confecciona varios informes. Un primer informe se titula "Informe sobre secuestro y homicidio en Bahía Blanca"13. Comienza con la denuncia en la Seccional segunda de Bahía Blanca por parte de la madre del Negrito, Marcela. Ella contaba cómo ingresaron cinco hombres desconocidos, con armas largas y sus rostros cubiertos y diciendo ser policías, en horas de la madrugada a su casa y se llevaron a su hijo en un auto Dodge verde sin chapas. Luego es mencionado en el informe el hallazgo del cuerpo de Jesús y la ubicación del mismo. La policía dice encontrar en el lugar 8 cápsulas servidas y 3 plomos.

El informe continúa con un apartado titulado "Antecedentes" en el cual se profundiza sobre la militancia política tanto del Negrito como de sus hermanas, de su padre y de su madre. Del Negrito dicen que ha sido visto con volantes del Frente Antiimperialista y por el Socialismo (FAS) y del Movimiento Sindical de Bases. También se remiten al año 1972, cuando Jesús aun estaba en el colegio secundario, la inteligencia consigna que "asistiendo al colegio secundario y en una prueba de castellano, tema libre, escribió la composición 
'El Buque Granaderos - Cárcel Flotante'”. Sobre las hermanas del Negrito, hablan de sus detenciones en el marco de un operativo "antisubversivo" en mayo de ese mismo año donde las encuentran repartiendo "material ideológico y propagandístico del FAS y del ERP”. Sobre Marcela, cuentan una de sus detenciones con su hija en un acto de solidaridad hacia el pueblo chileno contra el golpe a Allende, y al padre de Jesús lo ubican como "activista comunista", "relacionado al activismo de la UNS" y - afirman - que junto con su esposa "apoyarían a la organización Montoneros".

Los siguientes informes que la bonaerense realiza ya no están abocados al hecho del secuestro y del homicidio en sí mismo (aunque los siguen titulando de esa forma). Sino que se centran en observar quiénes habían concurrido al funeral del Negrito. Cabe aclarar, este funeral fue una gran marcha de distintos sectores políticos - casi 600 personas - que comenzó en la casa del Negrito, pasó por el centro de la ciudad hasta llegar a la casa velatoria, en todo este trayecto los asistentes llevaron el cajón en brazos.

El informe detalla las consignas que iban escribiendo con pintura por las calles de Bahía Blanca,

[...] salían de la columna individuos no identificados que escribían en las paredes de domicilios particulares con pinturas aerosol leyendas como: 'Ponce asesino del Negrito García', 'Ponce traidor a vos te va a pasar lo mismo que le pasó a Vandor', 'Cinco por uno no va a quedar ninguno'14.

También se detalla que durante el sepelio hubo oradores de distintos partidos y agrupaciones "hicieron uso de la palabra en forma breve representantes no identificados del PCR, PST, SB, FAS" y alguien "sospechado por su actividad de pertenecer al ERP". Mencionan a algunos concurrentes como el Dr. Pablo Lejarraga del partido Socialista Argentino. La inteligencia recogió los distintos volantes que fueron arrojando los manifestantes en el trayecto y detallaron las distintas agrupaciones que los firmaron, también anexaron un volante del PRT que denunciaba que "Ponce, sus matones y la Marina decidieron asesinar al Negrito García, obrero, militante activista del FAS". Este volante del PRT avanzaba en una interpretación sobre lo sucedido:

Anos 90, Porto Alegre, v. 19, n. 35, p. 111-140, jul. 2012 
El Negrito, obrero de la construcción, trabajaba en Interamericana de White. El gobierno antipopular y proimperialista que ahora tenemos cuenta con la UOCRA de Segundo Palma, Papagno, Juárez, Cruz, para vigilar, traicionar y robar a los obreros de la construcción. El Negrito lo vio claramente, vio de inmediato con qué habilidad se movían Juárez y Cruz para engañar a sus compañeros. Y contra esta nueva traición de los secuaces de Ponce, el Negrito comenzó a organizar a sus compañeros. Lo hizo colaborando con la Agrupación Combativa de Obreros de la Construcción que con sus posiciones clasistas mostró el correcto camino de la unidad y la lucha contra la patronal y la burocracia de la UOCRA ${ }^{15}$.

También esta carpeta contiene un teleparte firmado por el agente de la DIPBA José Héctor Ramos y por el Jefe Regional del mismo organismo Julio Tagliero, donde se especifican los estribillos que cantaron los presentes en el sepelio, algunas de las intervenciones de las agrupaciones. El informe concluye diciendo que al finalizar desconcentraron "sin incidentes".

Podemos ver que para la DIPBA resultaba importante detallar el evento del velorio porque concentraba a distintas agrupaciones militantes. Se dedicaron a contar qué hicieron y qué dijeron, así como también especificar los antecedentes políticos tanto de la víctima - el Negrito - como de toda su familia. Todo esto tenía más importancia para los servicios que ahondar en los posibles implicados en el homicidio.

Como un contrapunto de esta clase de informes, vale la pena mostrar qué es lo que dice la inteligencia sobre el asesinato a un agente de sus propias fuerzas. Me refiero al atentado contra el subcomisario José Héctor Ramos miembro de la Dirección de Inteligencia de la Policía de Buenos Aires, en marzo de 1975. Como similitudes vemos que también se detallan los asistentes al funeral. Entre ellos mencionan al intendente de Bahía Blanca Eugenio Martínez, al diputado nacional Rodolfo Antonio Ponce, al senador provincial Oscar Justiniano y a los distintos comisarios, jefes y oficiales de la Unidad Regional V, Ejército, Gendarmería, Prefectura y Policía 
Federal. También mencionan los comunicados solidaridad enviados por la CGT Regional y firmado por Ponce, allí se podía leer que:

[...] una vez más los mercenarios al servicio de la antipatria e ideologías extranjerizantes, pretenden en nuestra ciudad provocar el pánico y el terror produciendo hechos aberrantes contra humildes defensores del orden [...] estos elementos cipayos y asesinos que responden a los intereses de la Cuarta Internacional ${ }^{16}$.

O el comunicado de Remus Tetu, rector de la UNS quien decía:

[...] quiera Dios que este vil asesinato pueda servir para retemplar el espíritu de superiores y camaradas del Subcomisario José Héctor Ramos en la lucha sin descanso contra los apátridas que consumaron su muerte y la de tantos esforzados servidores públicos empeñados en la defensa de nuestras instituciones y modo de vida.

Fuera de esto, lo que me parece interesante para analizar es que casi todo el informe está dedicado a acumular pruebas de que el asesinato fue realizado por Montoneros ${ }^{17}$. Aquí si se ocupan de buscar los culpables y obviamente no existe ningún apartado llamado "Antecedentes" como en el caso del Negrito. Nadie investiga al muerto en este caso.

La misma lógica del informe sobre el asesinato de Jesús García se presenta cuando es denunciado por la dirección del diario local El Eco una nota enviada por correo postal al mismo y también al diario La Nueva Provincia firmada por la Triple A. Específicamente en la nota se sentencia a muerte a: Víctor Benamo, Eduardo Fachini, Julio Camblor, Raul Rayes, Lorenzo Ferrejans, Lidia Henares y Luis Fernandez Stacco. También amenazan al diario, planteando que si no se publicaba la amenaza en la próxima edición, este diario sería destruido: 
Sr. Director

Diario EL ECO

Brown 159

Bahía Blanca

Comunicado

Se comunica a la población en general que se ha reunido el tribunal del Pueblo de la Nacion para juzgar la conducta de diversos individuos de la zona habiendo sido encontrados culpables de delito de alta traición a la Patria y al gobierno Del Pueblo los que siguen a continuación:

Victor Benamo por vinculación con el ERP y defensa de agentes del imperialismo internacional

Eduardo Fachini por lo mismo

Julio Camblor por lo mismo

Raul Rayes por lo mismo

Lorenzo Ferrejans por vinculaciones con el ERP y entrega de la Universidad a la Sinarquía Internacional.

Lidia Henales por lo mismo

Luis Fernandez. Stacco por lo mismo

Todos los nombrados han sido sentenciados a muerte y serán ejecutados donde sean encontrados y en el momento propicio. Este comunicado debe ser publicado en la próxima edición porque si no será destruido el diario.

Esto sirve de comunicado a Víctor Benamo. A.A. ${ }^{18}$

Frente a la amenaza, el diario El Eco habría decidido no editar el ejemplar de ese día, entendiendo que esto iba en contra de las disposiciones legales que prohibían a los medios de prensa de la época publicar cualquier comunicado de grupos terroristas. En el caso de La Nueva Provincia se resolvió desestimar la intimación sin realizar ninguna denuncia.

Con respecto a los informes de DIPBA que dan cuenta de estos hechos, reiteramos, vemos la misma lógica que en el caso anterior, donde quienes resultan investigados son las víctimas en lugar de los victimarios. Podemos ver que luego de comunicar el hecho 
amenazante los servicios realizan el mismo apartado para recopilar los "Antecedentes" de cada una de los amenazados. En el caso de Víctor Benamo, por ejemplo, luego de presentar sus datos filiatorios y de origen, recorren su vida política desde el año 1958, consignando año a año los hechos que fueron considerados más relevantes; como sus distintas detenciones a disposición del Poder Ejecutivo Nacional, los actos políticos en los cuales participó, su cargo en la presidencia del Partido Justicialista local, su defensa a "elementos comunistas", su actuación como abogado de sindicatos, su actuación como interventor de la Universidad Nacional del Sur durante la gestión del Ministro de Educación Jorge Alberto Taiana, etc.

Con respecto al caso de Fernando Aldubino el informe solo se centra en dar datos precisos de cuándo fue denunciada su desaparición a la seccional y dónde y cómo encontraron su cuerpo. Se incluyen los datos de la autopsia que dan cuenta de los numerosos balazos. Y solo se agrega que era estudiante de Filosofía y Letras de la UNS pero que de él "no registra ningún tipo de antecedentes dentro del organismo" ". Sobre los asesinatos de Mario Golberg, Ester Giorzo y Hugo Alberto Vita, se adjuntan recortes de prensa sobre el hecho y nuevamente se detalla cuestiones referidas al lugar y forma de hallazgo de los cuerpos. Aunque también se intenta avanzar sobre algunas averiguaciones respectos a los vínculos personales entre Gorberg y Giorzo tomando el testimonio de un compañero de trabajo de Mario. Para finalmente terminar diciendo que esta persona "ignora si Ester o Mario tenían algún tipo de vinculación política o gremial"20. Aunque la bonaerense aquí tiene menos datos, no dejan de intentar avanzar sobre los "Antecedentes" o las procedencias políticas de las víctimas. Sobre los asesinos, aparece el mismo silencio que en los casos anteriores.

Hasta aquí, parecería que a la Policía de la Provincia de Buenos Aires solo le interesaba seguir los antecedentes de las víctimas de estos hechos y silenciar cualquier otro dato que no tuviera que ver con su trabajo de vigilancia al enemigo "apátrida". Sin embargo, encontramos un informe de DIPBA en donde esta lógica presenta algunos cambios.

El 27 de octubre de 1975 la inteligencia informaba sobre unos volantes que fueron encontrados en las calles titulados: “Qué pasa 
con la policía de Bahía Blanca" y firmado por el "Comando Pio XII"21. Vale la pena citar en extenso dicho comunicado:

Con el recambio de las autoridades de la Policía de la Provincia de Buenos Aires, operada un tiempo atrás en nuestra ciudad, nació en la población la esperanza de que se terminara definitivamente en este ámbito la subversión, el juego, la prostitución y la corrupción en general. Alentaron y alimentaron esas esperanzas las propias autoridades entrantes con arengas y declaraciones que hicieron públicas. Hoy la población ve con desagrado y desesperanza que todo cuanto se dijo no pasó del plano meramente declamativo, creador de falsas expectativas, y propiciador de brillantes negocios para la jefatura de la Unidad con todos los sucios sectores corruptos de la ciudad. Así es que la guerrilla y la subversión no se combaten; solamente se han ocupado de detener a giles insignificantes carentes de peso dentro de los sectores subversivos, dejando intactas las cabezas ideológicas ya sea por miedo, comodidad que les permita disfrutar de sus sucios negociados económicos o por inoperancia que finalmente se traduce en complicidad culposa.

En otro plano, se dedicaron a realizar ridículos, burdos e infantiles procedimientos y detenciones fugaces que movieron de risa, pero que provocaron la lógica inquietud en los sectores hacia los que estaban dirigidos, posibilitando de este modo la reactualización de las condiciones y aranceles a satisfacer para que la autoridad policial haga la vista gorda. Merced a eso es que nuevamente reinan en Bahía Blanca la prostitución, el juego y se mueven con soltura e impunidad los corruptos de toda laya.

Esto significa, en general, y en buen romance, que las nuevas autoridades policiales se dedicaron a reacomodar la situación para tornarla favorable a sus bastardos intereses materiales, sentándose luego en sus sillones a disfrutar el producido de sus sucios negociados hechos a espaldas de los ciudadanos de buena fe, traicionando las esperanzas de saneamiento moral y fecundo trabajo en pos de ideales y objetivos patrióticos, que ellos mismos habían alentado en una clara muestra de 
caradurez, inmoralidad, corrupción profesional y traición a la nacionalidad ${ }^{22}$.

La bonaerense en su informe infiere que este comunicado se relaciona directamente a una campaña respecto a las gestiones del nuevo Jefe de la Unidad Regional, el Comisario Mayor José Daniel Dallocchio; quien - según el informe - habría intentado erradicar "los grupos armados que venían actuando en el ámbito gremial (CGT y 62 organizaciones) y en el ámbito universitario"23. Se detalla que ante las medidas de Dallocchio se habría generado una reacción entre estos sectores, pero que la misma se habría disipado y en un principio

[...] fue superada mediante contactos con los dirigentes y autoridades, a quienes se les exhortó a encauzar la actividad desplegada por estos grupos intimándoseles a que desistieran de transitar y actuar con armas en la vía pública ${ }^{24}$.

En este informe se vincula el comunicado del "Comando Pío XII" con estos grupos armados que no solo son conocidos para la inteligencia, sino que incluso se los ha intentado "encauzar" mediante contactos con sus "dirigentes y autoridades". Se advierte un total conocimiento de las acciones de estos grupos, y se admite que no trabajan inorgánicamente sino respondiendo ordenes.

Pero el informe no termina allí, luego se admite que pese a las advertencias de la policía se suscitaron nuevos hechos por parte de estos grupos, hechos que llevaron a la detención de dos de estos personajes, uno de ellos "guardaespaldas del Diputado Nacional Rodolfo Ponce y últimamente integrante del grupo de seguridad de la UNS durante la gestión del profesor Remus Tetu" y el otro era

[...] dirigente de la Asociación de Empleados de la Junta Nacional de Granos, quienes circulaban en un vehículo de dicha repartición portando una pistola calibre 11, $25 \mathrm{~mm}$. Marca Colt nro. 54.901 y cargador nro. 22.487 y dos intercomunicadores marca SONY, entre otras $\operatorname{cosas}^{25}$. 
El nivel de detalle con el que habían consignado el tipo de armamento, da cuenta que la inteligencia tenía bien identificados a estos sujetos y el tipo de armas con las que se manejaban. Frente a esta detención, el agente que elabora el informe comunica que la misma "acentuó la tirantez del sector gremial en contra de la conducción de esta Policía, a quienes se le atribuyó que había animosidad hacia el sector sindical, tal como se anticipara a esa Central por memo. 250 de fecha 16 del cte. Dpto. D”. ${ }^{26}$ El agente de DIPBA reforzaba la conexión de estos sectores del sindicalismo con el volante del llamado "Comando Pio XII" comunicando los operativos de estos grupos en lugares nocturnos posiblemente vinculados a la prostitución. Se agregaba:

Coincidentemente con esta actitud, en forma confidencial se tuvo conocimiento que algunos elementos de la Juventud Sindical recorrieron pensiones y lugares de diversión nocturnos para detectar la existencia de alguna actividad ilegal vinculada con la prostitución, sabiéndose incluso que habrían efectuado algunos disparos con armas de fuego contra el frente del local- actualmente cerrado- denominado La Casona, ubicado en calle San Martín nro. 600 de Bahía Blanca, sin que el hecho tuviera ningún tipo de trascendencia ${ }^{27}$.

Solo a partir de los enfrentamientos que se empiezan a ver entre estas bandas parapoliciales y la policía, es que esta última comienza a problematizar el accionar de estos grupos en la ciudad y a visibilizarlos en sus informes de inteligencia, incluso admitiendo ciertos "diálogos" con sus dirigentes.

\section{Instituciones, discursos y prácticas. La violencia "antisubversiva" estatal.}

Marina Franco plantea que sobre el problema de la violencia habría que comenzar a mirar las responsabilidades del sistema político a partir de los efectos generados por un discurso que ampliamente repudiaba a la llamada "subversión": 
[...] por ello, interesa pensar los efectos representacionales de la articulación entre el discurso generalizado de repudio de la violencia y la denuncia creciente de la 'subversión' por parte de amplios sectores políticos, en particular de aquellos que representaban el consenso y la legitimidad democrática. (FRANCO, 2009, p. 22)

Respecto a los discursos de personalidades con legitimidad institucional, consultado sobre el asesinato del "Negrito" García, el Diputado Nacional Rodolfo Ponce declaraba para la prensa:

Se nos atribuyen asesinatos y se nos acusa de traidores, para tratar de desdibujar la imagen y el trabajo consecuente de quienes tenemos la responsabilidad histórica de desterrar definitivamente la violencia del país y de nuestra Bahía Blanca. Hoy vemos que quienes hasta ayer cantaban loas y estribillos arrogándose la muerte alevosa de muchos de nuestros compañeros dirigentes gremiales, políticos y militares, aparecen ahora en papel de víctimas, llámese FAR, Montoneros u otra organizaciones de esa naturaleza, pues últimamente no han tenido mínimo recato ni la mínima solemnidad que corresponde al acompañar a los restos de un trabajador asesinado [...] [ese acto] fue utilizado con medio de acción política enarbolando trapos rojos y otros elementos que están totalmente reñidos con el ser nacional. [...] Con esos procedimientos se quieren hacer cargos injuriosos y difamatorios y se quiere borrar toda una trayectoria de quienes siempre hemos estado al servicio de los más altos postulados de la Nación. Aprovecho esta ocasión para desafiar públicamente a que se me hagan los cargos concretos y legales, como corresponde, y que no se ataque cobardemente desde las paredes y el anonimato (LNP, 11/10/1974).

También Ponce meses más tarde, con el asesinato del subcomisario Ramos, repetiría sus acusaciones hacia los "apátridas", "de ideologías extranjerizantes" y "con intereses de la Cuarta Internacional". Recordemos que el interventor Remus Tetu no se quedaba 


\section{Ana Belén Zapata}

atrás, en sus discursos públicos arengaba contra los "apátridas" y en pos de la "defensa de las instituciones". Estas eran algunas de las denuncias que comúnmente aparecían en la prensa bahiense contra la creciente "subversión" repudiada por este tipo de políticos que formaban parte de esa "institucionalidad" ya sea ocupando una banca en el Congreso o un despacho en el Rectorado. Pero paralelamente, se contrataban sicarios a sueldo con fondos públicos como custodia de Tetu en la UNS.

En estos años la violencia "antisubversiva" parapolicial convivió con los operativos organizados desde las fuerzas del Estado. En un operativo “antisubversivo" del 31/01/1975 la policía allanó domicilio del estudiante Osvaldo Bidabehere, secuestrándole "material explosivo y bibliográfico de carácter subversivo” (LNP, 01/02/1975). El mismo día, efectivos del servicio de Informaciones de la Policía Bonaerense también allanaron la casa de Pablo Lejarraga. Recordemos que en el informe de inteligencia sobre el funeral de Jesús García se había especificado que Pablo Lejarraga había asistido al mismo.

"De la represión se ha pasado a la prevención" declaraba a la prensa el jefe de la Unidad Regional V, el comisario mayor José Daniel Dallochio (EL DIARIO, 03/08/1975). Dallochio dio cuenta de los resultados de sus operativos, habló de los delincuentes detenidos, las capturas por infracción a la ley de juegos prohibidos y la detención de 25 mujeres en situación de prostitución, "de peligroso ha vuelto a ser todo tranquilo" afirmaba el comisario que defendía la "acción preventiva". Fueron numerosos los operativos que comenzaron a realizarse en la ciudad. El 21/08/1975 se realizaron diversos operativos "antisubversivos” (EL DIARIO, 22/08/1975) Al día siguiente se conoció por la prensa que se habían detenido por la calle a dos estudiantes de la carrera de maestro mayor de obra en Construcciones de la Escuela de Educación técnica "Cesar Cipolletti”. Además, luego fueron allanados sus domicilios donde encontraron volantes de la UES, "bibliografía subversiva y material explosivo” (EL DIARIO, 23/08/1975) Dentro del mismo operativo y en un "acto relámpago" se intentó detener a un grupo de quince jóvenes reunidos en una fogata en la zona del paso a nivel del Ferrocarril Roca que "arrojaban panfletos". La policía solo llegó a detener a uno de ellos. 
En un editorial de LNP titulado La lucha de la 'Eterna Culpable' El respaldo que necesitaba la policía de Babía Blanca, el diario festejaba la duplicación del número de efectivos policiales en las calles bahienses y expresaba su reivindicación por la institución policial protagonista de "procedimientos riesgosos; acribillada por la guerrilla asesina". Sin quedarse atrás de la interna entre policía y "matones", LNP expresaba su repudio a lo que entendía como los métodos utilizados por Rodolfo Ponce - a quien no nombra explícitamente pero alude como "el legislador que hace fechorías en beneficio propio".

Cual signo de los tiempos, Bahía Blanca, aliviada ha visto como el tristemente célebre automóvil azul sin chapas bautizado "la fiambrera" 28 por el ingenio popular- ya no sale de noche a cumplir su tétrica recorrida, ni está permanentemente estacionado para escarnio de la ciudad a vista y paciencia de cuantos quisieran observarlo. No solo eso, en pocos días se han realizado jalonazos en su mayoría por el éxito de sendos procedimientos que le han vuelto a nuestra ciudad su tradicional tranquilidad. Ello demuestra el poder y la eficacia de nuestra policía consciente de su deber. Revela asimismo que solo dispensándole confianza y otorgándole los medios necesarios ésta puede desarrollar su actividad con probabilidades favorables (LNP, 03/09/1975).

A principios de noviembre de 1975 se anunciaron desde la prensa ejercicios "antisubversivos" en Bahía Blanca y en Coronel Rosales. Se prolongaron por varios días e involucraron a efectivos del Ejército, la Armada, la Prefectura Naval Argentina y la Policía de la Provincia de Buenos Aires. Casi como una antesala de lo que vendría meses luego con la dictadura, en un comunicado del Comando de Operaciones Navales, se solicitaba a la población la colaboración con las fuerzas y se establecían ciertas "recomendaciones" para los bahienses a los fines de "evitar confusiones cuyas consecuencias podrían ser irreparables” (LNP, 04/11/1975)

1) Transite por la vía pública en condiciones de poder identificarse, portando para ello la documentación correspondiente. 2) Respete las señales, barreras u otros indicadores 
visuales, que se encuentren próximos a instalaciones militares, de seguridad o policiales. 3) Si su desplazamiento es en vehículo, cumpla estrictamente las indicaciones de los centinelas que tienen a su cargo el control de la circulación para lo cual a) en caso de duda detenga el vehículo, apague las luces exteriores, encienda las lucen interiores; evite efectuar movimientos que puedan parecer sospechosos y espere las indicaciones o el procedimiento a seguir que le determine el personal militar, de seguridad o policial; 4) Aproximese con las ventanillas abiertas para poder escuchar las voces del personal militar, de seguridad o policial; 5) No olvide que debe portar la documentación correspondiente del vehículo que maneja, facilitando toda la tarea de control (LNP, 04/11/1975).

Sobre dicho operativo, el intendente Eugenio Martínez comunicaba a la ciudadanía que se estaba realizando un operativo "de práctica de guerra antisubversiva” (LNP, 04/11/1975) El mismo intendente de la ciudad ya hablaba de "guerra".

Hacia fines del '75, el Comandante de Operaciones Navales, Luis María Mendía anunciaba que sus fuerzas no se tomarían el acostumbrado receso de todos los años. Advertía que ese año la situación no permitía un alto en las tareas, ya que tenían el claro objetivo de "aniquilar la subversión y devolver la paz, la seguridad y el orden al pueblo argentino" y confirmaba: "tenemos sin duda alguna el poder militar necesario para logarlo". Por ello Mendía anunciaba que declaraba iniciado un nuevo período de actividades "en el que el adiestramiento y las operaciones de lucha contra la subversión pasarán a tener absoluta prioridad”. (LNP, 29/11/1975) 


\section{Algunas ideas finales}

Nosotros vamos a proceder de acuerdo con la necesidad cualquiera sean los medios. Si no hay ley, fuera de la ley también [lo] vamos a hacery lo vamos a hacer violentamente. Porque [a] la violencia no se le puede oponer otra cosa que la propia violencia Juan Domingo Perón ${ }^{29}$

A lo largo de este trabajo intentamos mostrar las características que asumió la "violencia de derecha" en la ciudad de Bahía Blanca, quiénes fueron sus víctimas, de qué forma se cometieron estos crímenes y cuáles fueron los lugares comunes del horror. Al observar estas cuestiones se vuelve inevitable detener la mirada en la articulación de estos hechos con un entramado más amplio dentro del sistema político que prestó estructuras institucionales para que se lleven a cabo con toda impunidad.

Observamos que la inteligencia de la provincia de Buenos Aires conocía muy bien a este tipo de bandas que operaban en la ciudad. No obstante, los informes que realizaban sobre sus víctimas solo se centraban en los "antecedentes" políticos o "subversivos" de las mismas.

En aras de luchar contra los llamados "apátridas" - denominación que compartían tanto políticos como mercenarios - se cometieron terribles masacres que fueron la antesala de la violencia organizada dentro del terrorismo de Estado. Para mencionar un ejemplo, Daniel Bombara, considerado el primer desaparecido de Bahía Blanca fue uno de los trabajadores no docentes cesanteados de la UNS por Remus Tetu. En este aspecto, vuelvo sobre las ideas de Marina Franco que me parecen reveladoras: "el problema no es entonces la 'legalidad' o la 'ilegalidad' de las acciones, sino el carácter excepcional y ascendente de esas medidas 'legales' fundadas en el estado de necesidad que llevó a la suspensión progresiva del Estado de derecho en nombre de su preservación" (FRANCO, 2012, p. 181)

Hay otro hecho que no quiero dejar de mencionar, y tiene que ver con la necesidad de empezar a estudiar los nexos entre las formas represivas anteriores a la dictadura y las que se produjeron durante la misma. A pocos meses del 24 de marzo de 1976 fueron 
secuestrados en sus casas dos sindicalistas gráficos, Enrique Heinrich y Miguel Ángel Loyola. Años antes habían protagonizaron conflictos laborales con La Nueva Provincia, el diario amigo de la Marina. Ellos fueron "marcados" tanto desde la inteligencia de la Policía bonaerense como del servicio de inteligencia Naval, acusados de ser la "guerrilla sindical" dentro de ese diario. El 4 de julio del '76 fueron encontrados sus cuerpos acribillados a balazos, en el paraje la "Cueva de los leones" a las afueras de la ciudad. Fueron asesinados de la misma forma en la que eran asesinados usualmente las víctimas de la Triple $A$, con sus cuerpos totalmente baleados y en un lugar donde comúnmente estas bandas "tiraban" sus muertos.

El caso anterior adquiere singularidad ya que en él se repite - dentro del contexto dictatorial ${ }^{30}$ - un modus operandi propio de la violencia parapolicial de años anteriores. Incluso hoy podemos conocer a partir de la nómina del personal civil de inteligencia que operó en Bahía Blanca entre 1976 y 1984 - publicada por el Archivo Nacional de la Memoria - que algunos de los "custodios del orden" de 1975, terminaron formando parte de los servicios de inteligencia durante la dictadura. Este hecho no hace más que marcar los hilos de continuidad en términos represivos entre los ambos contextos.

PARA-POLICE'S VIOLENCE IN BAHÍA BLANCA, 1974-1976. THE THIN BORDERS BETWEEN THE INSTITUTIONAL AND ILLEGAL PRACTICES IN THE SO-CALLED “ANTISUBVERSIVE STRUGGLE”

Abstract: In this article we analyze some aspects of the violence carried out by para-police forces in the city of Bahia Blanca-Province of Buenos Aires- between 1974 and 1976. We can talk about this period as a time which gave birth to certain conditions of possibility for democratic breakdown that occurred with the coup d'état in Argentina 1976. This idea goes through this article where we analyze the ways that acquired the right-wing violence in Bahia Blanca. Occasionally we wonder: which were the main characteristics of this violence before 1976?, how much did know the Buenos Aires's Police Intelligence (DIPBA) about this situation?, and how were overlapped practices and discourses of actors, inside the political system with the illegal and parapolice-like actions in the so-called "antisubversive struggle" already instilled prior to the coup d'etat?

Keywords: Para-police's violence. Repression. Intelligence. Illegality. 


\section{Notas}

${ }^{1}$ La cita corresponde a una discusión en el Congreso Nacional entre los diputados Héctor Sandler y Rodolfo Ponce. Sandler denunciaba las reiteradas amenazas que venía sufriendo por parte de la Triple A y las provocaciones que, en la misma lógica, se realizaban a su persona desde la revista "El Caudillo de la tercera posición" de Felipe Romeo. En el marco de esa denuncia Sandler ejemplifica el accionar de grupos de choque con un hecho ocurrido en Bahía Blanca y protagonizado por los matones de la CGT en la toma de la Universidad Tecnológica Nacional en septiembre de 1974. Frente a estos dichos Rodolfo Ponce responde enérgicamente llamando mentiroso a Sandler. Este último contestó con la cita en referencia.

${ }^{2}$ Algunas de ellas como la Juventud de Trabajadores Peronistas (JTP), la Juventud Universitaria Peronista (JUP) la Unión de Estudiantes Secundarios (UES) el Peronismo de Base, etc.

${ }^{3}$ En referencia a estudios sobre las organizaciones de derecha como la Triple A véase, entre otros: (PAINO, 1984); (JANSEN, 1987); (WERNER; AGUIRRE, 2007); (MARONGIU, 2007); (SERVETTO, 2008); (BESOKY, 2010); (CARNAGUI, 2010); (ROSTICA, 2011); (LARRAQUY, 2011)

${ }^{4}$ La ciudad de Bahía Blanca se encuentra ubicada en el sudoeste de la provincia de Buenos Aires. Según el Censo Nacional de Población de 1970, tenía 182.000 habitantes lo que la hacía una ciudad de pequeñas a medianas proporciones en comparación a urbes más pobladas de Argentina. Es una ciudad portuaria y agroexportadora, de características comerciales más que industriales. Se encuentra fuertemente militarizada ya que reúne numerosas fuerzas de seguridad, entre ellas la Base Naval "Puerto Belgrano" y el V Cuerpo de Ejército. Posee una dinámica cultural y educativa importante al ser sede de la Universidad Nacional del Sur y de la Universidad Tecnológica Nacional.

${ }^{5}$ La Nueva Provincia es un medio de comunicación de importante distribución en todo el sudoeste bonaerense, fue fundado en agosto de 1898 por Enrique Julio. La línea editorial de este diario estuvo históricamente alineada a las Fuerzas Armadas. Siempre se caracterizó por sus posiciones antiperonistas, anitimarxistas y progolpistas en los distintos contextos políticos que vivió el país a lo largo del siglo XX.

${ }^{6}$ Entrevista a la madre de Jesús García, 9 de septiembre de 2007 realizada por Julia Giménez (GIMÉNEZ, 2008, p. 124).

${ }^{7}$ Rodolfo Antonio Ponce era un dirigente sindical proveniente de la Unión de Recibidores de Granos y Afines (URGA) Para estos años se desempeñaba como Secretario General de la Central General de Trabajadores (CGT) local e integrante de la mesa nacional de las 62 organizaciones. Luego de las elecciones de 1973 ingresó al Congreso de la Nación como Diputado Nacional por el Frente

Anos 90, Porto Alegre, v. 19, n. 35, p. 111-140, jul. 2012 
Justicialista de Liberación (FREJULI). Era un peronista ortodoxo que hacía oír su fuerte repudio hacia los "extremistas" o "izquierdistas" que "se disfrazan de peronistas" - haciendo alusión a los militantes del PRT-ERP, Montoneros y distintas ramas de la Tendencia peronista.

${ }^{8}$ Entrevista a la hermana de Jesús García, 9 de noviembre de 2007 realizada por Julia Giménez (GIMÉNEZ, 2008, p. 125).

${ }^{9}$ En el comunicado público por el cual Montoneros asumió la autoría del hecho, señalaban a Ramos como miembro de la Triple A en Bahía Blanca. Archivo ex DIPBA. Mesa DS, Carpeta Varios, Legajo n 3061

${ }^{10}$ En 1975 con la misión del Ministro de Educación Oscar Ivanissevich, fue designado como interventor de la Universidad Nacional del Sur, Remus Tetu un exiliado rumano militante de la organización Guardia de Hierro de tendencia filofascista - En su gestión Tetu tomó numerosas medidas tendientes a eliminar la llamada "penetración ideológica marxista" de la universidad. Dejó cesantes a docentes, estudiantes o personal no docente considerado "subversivo", restringió el ingreso a la universidad; suspendió la inscripción y el dictado de algunas carreras; despidió a 225 docentes; prohibió asambleas, centros de estudiantes y cátedras paralelas, entre otras medidas.

${ }^{11}$ Video documental "Watu, ¿`sabes quien fue?". Testimonio Miguel Pereyra testigo presencial del asesinato de Watu.

${ }^{12}$ La Dirección de Inteligencia de la Policía de Buenos Aires (DIPBA) tiene sus antecedentes en la Oficina de Movimiento Político, la Dirección de Orden Público y la Sección Orden Social que ya funcionaba en el país desde la década del '30. Fue en el marco de la llamada Revolución Libertadora de 1955 que se disolvió la Dirección de Orden Público y fue intervenida por las Fuerzas Armadas para su reorganización. La creación de la DIPBA se realiza dentro del contexto de la proscripción al peronismo a nivel nacional y de la Guerra Fría en términos internacionales. Desde 1998 este organismo fue disuelto y los documentos de su archivo son conservados y están siendo digitalizados por la Comisión Provincial por la Memoria en La Plata. Estas fuentes fueron abiertas al público en el año 2003.

${ }^{13}$ Archivo ex DIPBA. Mesa DS, Carpeta Varios, Legajo n ${ }^{\circ} 2024$

${ }^{14}$ Archivo ex DIPBA. Mesa DS, Carpeta Varios, Legajo n 2024

${ }^{15}$ Archivo ex DIPBA. Mesa DS, Carpeta Varios, Legajo n 2024

${ }^{16}$ Archivo ex DIPBA. Mesa DS, Carpeta Varios, Legajo n 3061

${ }^{17}$ Se detalla el momento de hallazgo del comunicado de Montoneros atribuyéndose el hecho, se acopian fotografías de las calles bahienses con pintadas que daban cuenta de lo mismo, se adjuntan volantes tanto de Montoneros como de la JUP. En ellos Montoneros por su parte explica su justificación del asesinato: "Esta lacra que continuó consecuentemente su camino de enemigo de la causa popular, uniéndose a la banda de las AAA, grupo parapolicial inventado por López Rega 
e Isabel para asesinar a los militantes [...]" El volante de la JUP es mucho más general y denuncia los asesinatos de Aldubino y el atentado a Rigati que fueron un día después del asesinato de Ramos: "Los matones de Ponce, trasladándose en el coche del rector Remus Tetu, asesinan en la UNS al estudiante David Cilleruelo (Watu) secretario de la Federación Universitaria de la Bahía Blanca (FUBB). Asesinato del compañero Fernando Aldubino, estudiante de Filosofía y Trabajador Municipal. Destrucción del domicilio del compañero Jorge Riganti, Vicepresidente de la FUBB. 800 estudiantes sin carrera, 350 docentes cesantes, 10 carreras cerradas, 22 trabajadores no docentes amenazados para exigirles su renuncia. Los matones de Ponce: Argibay, Sañudo y otros, con armas de la Marina, con protección policial y contratados por Remus Tetu. 'Guadan el orden' armas a la vista, en la UNS como en la UTN intimidando y asesinando compañeros." Archivo ex DIPBA. Mesa DS, Carpeta Varios, Legajo n 3061

${ }^{18}$ Archivo ex DIPBA. Mesa DS, Carpeta Varios, Legajo n 2154

${ }^{19}$ Archivo ex DIPBA. Mesa DS, Carpeta Varios, Legajo no 3122

${ }^{20}$ Archivo ex DIPBA. Mesa DS, Carpeta Varios, Legajo no 4291

${ }^{21}$ Se conoce al llamado "Comando Moralizador Pio XII" como una organización parapolicial de la provincia de Mendoza que actuó desde mayo de 1975 y estuvo vinculada al jefe de la policía provincial Julio Cesar Santuccione. Esta organización tenía como víctimas especialmente a las mujeres en situación de prostitución las cuales eran torturadas y asesinadas siendo sus cuerpos eran arrojados en zonas de montaña aunque también incluían atentados con bombas a clubes nocturnos, y asesinatos a "rufianes". También aparece vinculado al Comando Anticomunista de Mendoza (CAM) que junto con el Comando Pío XII se habrían constituido para defender a la población de la "penetración marxista" en el primer caso y para resguardar la "moral” en el segundo. (Rodríguez Agüero, 2006)

22 Archivo ex DIPBA. Mesa DS, Carpeta Varios, Legajo n 4291

${ }^{23}$ Archivo ex DIPBA. Mesa DS, Carpeta Varios, Legajo no 4291

${ }^{24}$ Archivo ex DIPBA. Mesa DS, Carpeta Varios, Legajo no 4291

${ }^{25}$ Archivo ex DIPBA. Mesa DS, Carpeta Varios, Legajo n 4291

${ }^{26}$ Archivo ex DIPBA. Mesa DS, Carpeta Varios, Legajo no 4291

${ }^{27}$ Archivo ex DIPBA. Mesa DS, Carpeta Varios, Legajo n ${ }^{\circ} 4291$

28 "La fiambrera" era como comúnmente denominaba la población bahiense de la época al vehículo con el cual se secuestraba y luego asesinaban militantes. Algunos entrevistados la llamaban "la fiambrera de la CGT de Ponce".

${ }^{29}$ Clarin, 23/02/1974 Citado en Franco, 2012, p. 72

${ }^{30}$ En este contexto se observan otro tipo de procedimientos. Por lo general las víctimas eran secuestradas por alguna de las fuerzas y eran llevadas a algunos de los centros clandestinos de la ciudad, ya sea el complejo denominado "La Escuelita" cercano al V Cuerpo de Ejército, el buque "ARA 9 de Julio" u otras dependencias 


\section{Ana Belén Zapata}

de la Base Naval "Puerto Belgrano" y de Infantería de Marina "Baterías" donde la mayoría sufrían torturas y malos tratos. Los detenidos que eran asesinados en cautiverio a veces aparecían nombrados en los ficticios "enfrentamientos" inventados por las fuerzas y publicados por LNP. Los detenidos que salvaban sus vidas puestos a disposición del Poder Ejecutivo Nacional, generalmente eran "blanqueados" en la Cárcel de Villa Floresta, aunque no estaban absueltos de recibir tormentos en interrogatorios también allí.

\section{Referencias}

AGÜERO, Laura Rodríguez. Las mujeres en prostitución como blanco del accionar represivo: el caso del Comando Moralizador Pío XII, Mendoza 1974-1976 en CD de VIII Jornadas Nacionales de Historia de las Mujeres, III. Congreso Iberoamericano de Estudios de Género, Universidad Nacional de Córdoba, Villa Giardino, Córdoba, 2006.

BESOKY, Juan Luis. La revista El Caudillo de la Tercera Posición: órgano de expresión de la extrema derecha. In: Conflicto Social, año 3, n. 3, jun., Buenos Aires, 2010.

CALVEIRO, Pilar. Antiguos y nuevos sentidos de la política y la violencia. In: Lucha Armada en la Argentina, n. 4, Buenos Aires, 2005

CARNAGUI, Juan Luis. La construcción de un sentido común sobre la "derecha peronista" de los años '70. In: Antitesis, v. 3, n. 6, Londrina, 2010.

DOMINELLA, Virginia. El fermento en la masa. La Juventud Universitaria Católica en Bahía Blanca, entre la efervescencia política y la oleada represiva de la Triple A 1968-1975. Tesina de Licenciatura. Defendida en el Departamento de Humanidades de la UNS el 19 de mayo, Bahía Blanca, 2010.

FRANCO, Marina. Violencia política, subversión y guerra entre 1973 y 1976. Discursos públicos y prácticas políticas. In: CD de XII Jornadas de InterescuelasDepartamentos de Historia, Unversidad Nacional del Comahue, Bariloche, 2009. . Un enemigo para la nación. Orden interno, violencia y 'subversión', 1973-1976. Fondo de Cultura Económica, Buenos Aires, 2012.

FUNES, Patricia. Los libros y la Noche. Censura, cultura y represión en Argentina a través de los Servicios de Inteligencia del Estado. In: Dimensores, n. 19, Vitória (ES), NPIH/Ufes, p. 133-155, 2007. 
GIMÉNEZ, Julia. Ciudad de Perros. Historias de militancia y recorridos del PRT-ERP por la ciudad de Bahía Blanca. Tesina de Licenciatura. Defendida en el Departamento de Humanidades de la UNS el 19 de diciembre, Bahía Blanca, 2008. GONZÁLEZ, Jansen. La Triple A. Buenos Aires: Contrapunto, 1987.

LARRAQUY, Marcelo. López Rega, El peronismo y la Triple A. Buenos Aires: Aguilar, 2011.

LOBBE, Héctor. La Guerrilla fabril. Clase obrera e izquierda en la Coordinadora de Zona Norte del Gran Buenos Aires (1975-1976). Buenos Aires: Ediciones RyR, 2009.

MARONGIU, Federico. La ultraderecha en el gobierno justicialista de 19731976: Triple A, Juventud peronista de la República Argentina y Concentración Nacional Universitaria. In: CD de Jornadas Interescuelas/Departamento de Historia, Tucumán, 2007.

PAINO, Horacio. Historia de la Triple A. Montevideo: Editorial Platense S. A, 1984.

ROBLES, Andrea. La Triple A y la política represiva del gobierno peronista. In: RUTH, Werner; AGUIRRE, Facundo. Insurgencia obrera en la Argentina 1969-1976. Clasismo, coordinadoras interfabriles y estratégicas de irquierda. Buenos Aires: Ediciones IPS, p. 483-534, 2007.

ROSTICA, Julieta. Apuntes sobre la Triple A. Argentina, 1973-1976. In: Desafíos 23-II, p. 21-51, 2011.

SERVETTO, Alicia. Memorias de intolerancia política: las víctimas de la Triple A (Alianza Argentina Anticomunista). In: Antítesis, v. 1 n. 2, Londrina, 2008.

Recebido em: 29/05/2012

Aprovado em: 10/09/2012 